\title{
Contest Design: An Experimental Investigation
}

\author{
Roman M. Sheremeta * \\ Argyros School of Business and Economics, Chapman University, \\ One University Drive, Orange, CA 92866, U.S.A.
}

March 25, 2009

\begin{abstract}
This paper experimentally compares the performance of four simultaneous lottery contests: a grand contest, two multiple prize settings (equal and unequal prizes), and a contest which consists of two subcontests. Consistent with the theory, the grand contest generates the highest effort levels among all simultaneous contests. In multi-prize settings, equal prizes produce lower efforts than unequal prizes. The results also support the argument that joint contests generate higher efforts than an equivalent number of subcontests. Contrary to the theory, there is significant over-dissipation. This over-dissipation can be partially explained by strong endowment size effects. Subjects who receive higher endowments tend to over-dissipate, while such over-dissipation disappears when the endowments are lower. This behavior is consistent with the predictions of a quantal response equilibrium. We also find that less risk-averse subjects over-dissipate more.
\end{abstract}

JEL Classifications: C72, C91, D72

Keywords: rent-seeking, contest, contest design, experiments, risk aversion, over-dissipation

Corresponding author: Roman M. Sheremeta; E-mail: sheremet@,chapman.edu

* I am particularly grateful to Tim Cason for excellent guidance and support. I thank Jason Abrevaya, Marco Casari, Subhasish Modak Chowdhury, Dan Kovenock, Jingjing Zhang, anonymous referees, and the associate editor of this journal for their constructive comments, as well as seminar participants at Purdue University for helpful suggestions. This research has been supported by National Science Foundation Grant (SES-0751081). Any remaining errors are mine.

\section{Introduction}


Costly competitions between economic agents are often portrayed as contests. Examples range from college admissions and competition for promotions to global relationships in which different countries and political parties expend resources to lobby their own interests (Krueger, 1974; Tullock, 1980). The variety of economic situations that can be described as contests has attracted enormous attention from economic theorists. The main focus of this literature is the relationship between the setup of rent-seeking contests and the strategic behavior of contestants. It is well recognized that strategic behavior is sensitive to different contest rules. Therefore, depending on the objective, a careful design of each contest is required.

Despite the abundance of theoretical work on contest design, no experimental research has specifically compared alternative contest mechanisms. ${ }^{1}$ To begin to bridge this gap, this study investigates and compares the performance of four simultaneous contests: a grand contest, two multi-prize settings (equal and unequal prizes), and a contest which consists of two subcontests. Consistent with the theory, we find that the grand contest generates the highest effort levels among all simultaneous contests. In multi-prize settings, equal prizes produce lower efforts than unequal prizes. Our results also provide strong empirical support for the argument that joint contests generate higher efforts than an equivalent number of subcontests. However, contrary to the theory, we find significant over-dissipation in all contests. This over-dissipation can be partially explained by strong endowment size effects. Subjects who receive higher endowments tend to over-dissipate, while such over-dissipation disappears when the endowments are lower. This behavior is consistent with the predictions of a quantal response equilibrium. Finally, there is a strong heterogeneity between subjects and individual expenditures

\footnotetext{
${ }^{1}$ Several experimental studies looked at the design of rank order tournaments (Orrison et al., 2004; Harbring and Irlenbusch, 2003, 2005) and fund-raising lotteries (Morgan and Sefton, 2000; Lange, 2007). The most closely related work to ours is done by Müller and Schotter (2007) who analyze the influence of prizes in all-pay auction with heterogeneous agents following the theoretic work by Moldovanu and Sela (2001). The main focus of Müller and Schotter (2007) is the effect of heterogeneity in abilities on the efforts expended.
} 
over time, which is clearly inconsistent with the symmetric pure strategy equilibrium. The deviations from the symmetric equilibrium can be explained to some extent by differences in risk preference and probabilistic nature of lottery contests.

A number of theoretical papers have been devoted to the design of an optimal contest that generates the highest revenue - the total amount of effort expended by the contestants. A common motivation for such research is the objective of various agencies (political parties, lottery administrators, and economic groups) to maximize earnings by extracting the highest effort from the contestants. Gradstein and Konrad (1999), for example, provide a rationale for a multi-stage contest design by endogenizing the choice of contest structure. They show that, depending on a return to scale parameter of the contest success function, a multi-stage contest may induce higher effort by the participants than a one-stage contest. In the same line of research, Baik and Lee (2000) study a two-stage contest with effort carryovers. They demonstrate that, in the case of player-specific effort carryovers, the rent-dissipation rate (defined as the ratio of the expended total effort to the value of the prize) increases in the carryover rate and the rent is fully dissipated with carryover rate equal to one. Finally, Fu and $\mathrm{Lu}$ (2007) investigate the optimal structure of a multistage sequential-elimination contest with pooling competition in each stage. They demonstrate that the optimal contest eliminates one contestant at each stage until the finale in which a single winner takes the entire prize.

Overall, it is generally observed in the contest literature that pooling competition generates higher dissipation rates (Clark and Riis, 1998; Amegashie, 2000; Fu and Lu, 2009; Moldovanu and Sela, 2006). ${ }^{2}$ Clark and Riis (1998) show that the income maximizing contest administrator obtains the highest rent-seeking effort when, instead of many small prizes, a large

\footnotetext{
${ }^{2}$ For more multiple prize contests see Glazer and Hassin (1988), Barut and Kovenock (1998), and Che and Gale (2003).
} 
prize is provided. $\mathrm{Fu}$ and $\mathrm{Lu}(2009)$ demonstrate that the rent dissipation rate increases when the number of contestants and prizes are scaled up. Therefore, the authors conclude that a grand contest generates higher revenue than any set of subcontests. Moldovanu and Sela (2006) investigate a similar problem under the structure of all-pay auctions where all players know their own abilities and the distribution of abilities in the population. The major finding of Moldovanu and Sela (2006) is that independently of the number of contestants and the distribution of abilities, a grand contest generates the highest revenue when the cost function is either linear or concave. However, it is not always the case that pooling competition generates the highest efforts. For example, if the contestants have convex costs several prizes may be optimal (Moldovanu and Sela, 2001; Kräkel, 2006). The non-optimality of a single large prize can also occur in a contest where players have commonly known but different abilities (Szymanski and Valletti, 2005).

The empirical evidence for contest design theory is mixed (Szymanski, 2003). Maloney and McCormick (2000), for example, analyze responses of individual runners to prizes in foot races. They find a significant relation between the performance and the prize value. Consistent with Lazear and Rosen (1981), higher prize values cause higher effort levels. Similar to Maloney and McCormick (2000), Lynch and Zax (2000) examine data on road races in the United States. They find that the performance increases in response to larger prize spreads. However, when controlled for ability factor, the impact of the prize spread disappears. The authors thus conclude that the larger prize spreads produce better performance not because they encourage all runners to run faster but because they attract faster runners.

To complement the existing empirical studies and to further investigate contest design problem we conduct a controlled experiment. The experiment is based on the theoretical model 
presented in Section 2. Section 3 provides experimental design and testable hypotheses. Section 4 reports the results of the experiment. Section 5 offers alternative explanations for overdissipation and heterogeneity observed in the experiment and Section 6 concludes.

\section{Theoretical Model}

Denote by $C \equiv C\left(N,\left\langle V_{S}\right\rangle_{s=1}^{K}\right)$ a contest with $N$ identical risk-neutral players who are competing for $K$ prizes of a common value $V_{s}, s=1, \ldots, K{ }^{3}$ No player may win more than one prize and there are more players than available prizes. Each player $i$ chooses irreversible effort level of $e_{i}$ to influence the probability of winning. Let $\Omega_{s}$ be the set of remaining $(N-s+1)$ players who have not won one of the $(s-1)$ prizes. Then the conditional probability that a contestant $i$ wins the $s$-th prize is given by a lottery contest success function:

$$
p_{i}\left(e_{i}, e_{-i} ; \Omega_{S}\right)=\frac{e_{i}}{e_{i}+\sum_{j \in \Omega_{S}} e_{j}}, \quad i \neq j
$$

The efforts are often raised to an exponent term to indicate the sensitivity of a contest.

Our reasons for choosing this specific contest success function is that it is simple enough for subjects to understand and it is also commonly used in most of the rent-seeking contest literature, including virtually all of the experimental contest literature. It is important to emphasize, however, that the simplicity of (1) does not affect the comparative statics predictions of the theory (Clark and Riis, 1998; Fu and Lu, 2009).

We concentrate our analysis on the symmetric pure strategy Nash equilibrium of the game. The expected payoff of player $i, E\left(\pi_{i}\right)$, is derived by multiplying player $i$ 's probability of winning each prize, $p_{i}\left(e_{i}, e_{-i} ; \Omega_{S}\right)$, by its value, $V_{S}$. Since we are considering symmetric

\footnotetext{
${ }^{3}$ For theoretical and experimental analysis of heterogeneous agents in lottery contests see Harbring et al. (2007), Lange et al. (2007), and Sheremeta (2009).
} 
equilibrium the efforts made by other players $i \neq j$ can be denoted as $e$. Therefore, the probability that $i$ wins the first prize is $e_{i} /\left(e_{i}+(N-1) e\right)$. If $i$ does not win the first prize, his conditional probability of winning the second prize is the product of the probability that $i$ does not win the first prize and the probability that he does win the second prize. Applying this reasoning we can write player $i$ 's expected payoff as:

$$
\begin{aligned}
E\left(\pi_{i}\right) & =\frac{e_{i}}{e_{i}+(N-1) e} V_{1}+\frac{(N-1) e}{e_{i}+(N-1) e} \frac{e_{i}}{e_{i}+(N-2) e} V_{2}+ \\
& +\frac{(N-1) e}{e_{i}+(N-1) e} \frac{(N-2) e}{e_{i}+(N-2) e} \frac{e_{i}}{e_{i}+(N-3) e} V_{3}+\cdots+\prod_{h=1}^{K-1} \frac{(N-h) e}{e_{i}+(N-h) e} \frac{e_{i}}{e_{i}+(N-K) e} V_{K}-e_{i}
\end{aligned}
$$

The expected payoff (2) is based on the assumptions that players are risk-neutral and have linear costs. However, by relaxing the linearity of costs assumption the comparative statics predictions of the theory are not affected. In fact, in the derivation of the equilibrium, Clark and Riis (1998) use a nonlinear cost function $e_{i}^{1 / r}$ instead of $e_{i}$, where $r>(<) 1$. Differentiating (2) with respect to $e_{i}$ leads to the equilibrium effort level in the contest $C\left(N,\left\langle V_{s}\right\rangle_{s=1}^{K}\right):{ }^{4}$

$$
e^{*}=\frac{1}{N} \sum_{s=1}^{K} V_{s}\left(1-\sum_{h=0}^{s-1} \frac{1}{N-h}\right)
$$

Formula (3) is the building block of the experimental design used in this study. It shows that the effort level of each contestant depends on the number of contestants, the number of prizes, the value of prizes, and the ordering of prizes. Especially interesting is the "placement effect": the contest administrator can increase the effort level (3) by reducing the value of an early prize $V_{S}$ and increasing the value of a later prize $V_{s-1}$ by the same amount. Taking into account that the revenue collected by the administrator is simply the summation of all individual efforts, the placement effect justifies the use of a large single prize to maximize the revenue collected in the contest.

\footnotetext{
${ }^{4}$ General conditions for existence of the equilibrium and detail derivations are shown in Clark and Riis (1998).
} 


\section{Experimental Design and Procedures}

\subsection{Treatments and Hypothesis}

Suppose there are $N$ players who are willing to participate in a contest. The administrator has a budget $V$ and he wants to maximize total revenue extracted from contestants. The administrator must choose how to organize this contest. The simplest way to do this is a simultaneous move grand contest, in which all players are pooled into one large group with only one large prize. This type of contest is the baseline treatment of this study.

Treatment GC: The first contest is a grand contest $C_{1}(N, V)$ in which all $N$ contestants are in the same group and they compete for a single prize of value $V$. Applying (3) and summing over all contestants' efforts, the total revenue collected in $C_{1}$ is

$$
T R_{G C}=V\left(1-\frac{1}{N}\right)
$$

If the prize $V$ is divisible the administrator must choose how to divide it. He can divide the prize into several unequal prizes or he can make all prizes equal. The next two treatments investigate these alternatives.

Treatment UC: In contest $C_{2}\left(N,\left\langle V_{1}, V_{2}\right\rangle\right)$ all contestants are competing for two unequal

prizes $V_{1}=\frac{3}{4} V$ and $V_{2}=\frac{1}{4} V$. A 3 to 1 ratio of splitting the prize has been proposed by Galton (1902). Note, that the sum of $V_{1}$ and $V_{2}$ yields the combined prize of value $V$. The total revenue generated by this contest is

$$
T R_{U C}=V\left(1-\frac{1}{N}-\frac{1}{4(N-1)}\right) .
$$

Treatment EC: In the third contest, $C_{3}\left(N,\left\langle V_{1}, V_{2}\right\rangle\right)$, all contestants compete for two prizes of the same value $V_{1}=V_{2}=\frac{1}{2} V$. The total revenue collected is derived from formula (3): 


$$
T R_{S C}=V\left(1-\frac{1}{N}-\frac{1}{2(N-1)}\right)
$$

Frequently, instead of putting the contestants into one large group, they are split into several subgroups. In these cases the competition goes on within each group. As a result, the contest organizer collects the revenue from each subcontest separately.

Treatment SC: This last simultaneous contest treatment consists of two separate and identical contests $C_{41}=C_{42}=C\left(\frac{1}{2} N, \frac{1}{2} V\right)$. The SC treatment resembles the EC treatment, but instead of competition within the same group, contestants are split into two equal size groups $\frac{1}{2} N$ and the winner of each group receives a prize value $\frac{1}{2} V$. The total revenue collected in both $C_{41}$ and $C_{42}$ is

$$
T R_{S C}=V\left(1-\frac{2}{N}\right)
$$

Based on the four treatments, we can formalize the following three hypotheses:

Hypothesis 1. Grand contest (GC) generates the highest revenue among all simultaneous contests.

This hypothesis follows directly from the four treatments listed above. It can also be derived from Clark and Riis (1998), who showed that an administrator who wishes to maximize the revenue should combine all of the prizes into one grand prize.

Hypothesis 2. In multi-prize settings, equal prizes (EC) produce lower efforts than unequal prizes (UC).

This hypothesis comes from the observation that increasing the value of the first prize, while decreasing the value of the second prize by the same amount, increases effort expenditures. Therefore, the UC treatment should generate higher revenue than the EC treatment, since in the UC treatment the first prize is $V_{1}=\frac{3}{4} V$ while in the EC treatment the first prize is $V_{2}=\frac{1}{2} V$. Our 
final hypothesis is based on a recent study by $\mathrm{Fu}$ and $\mathrm{Lu}$ (2009), who showed that the joint contest generates higher revenue than any set of subcontests.

Hypothesis 3. Joint contest (EC) generates higher efforts than equivalent number of subcontests (SC).

In summary, the four contests can be ranked by the total revenue collected: $T R_{G C}>$ $T R_{U C}>T R_{E C}>T R_{S C}$. If revenue maximization is the objective of the administrator then the grand contest should be preferred over all other contests, unequal prize splitting should be preferred over equal prize splitting, and a joint contest should be preferred over two equivalent subcontests.

\subsection{Experimental Procedures}

The experiment consists of four different contests. Table 3.1 shows the equilibrium effort levels, revenue generated by each contest, and dissipation rates, defined as the total expenditures divided by the total value of the prize, for $N=4$ and $V=120$.

Table 3.1 - Experimental Design and Nash Equilibrium Predictions

\begin{tabular}{cccccccc}
\hline \hline \multirow{2}{*}{ Treatment } & Number of Players per & Prizes per & Value of the & \multicolumn{2}{c}{ Equilibrium } & \multicolumn{2}{c}{ Dissipation } \\
\cline { 6 - 7 } & Groups & Group, $N$ & Group, $s$ & Prize, $V$ & Effort, $e$ & Revenue, $T R$ & Rate \\
\hline GC & 1 & 4 & 1 & 120 & 22.5 & 90 & 0.75 \\
UC & 1 & 4 & 2 & 90,30 & 20.0 & 80 & 0.67 \\
EC & 1 & 4 & 2 & 60,60 & 17.5 & 70 & 0.58 \\
SC & 2 & 2 & 1 & 60 & 15.0 & 60 & 0.50 \\
\hline
\end{tabular}

The experiment used 132 subjects drawn from the population of undergraduate students at Purdue University. Computerized experimental sessions were run using z-Tree (Fischbacher, 2007) at the Vernon Smith Experimental Economics Laboratory. We ran eleven experimental sessions with two treatments in each session as in Table 3.2. There were 12 subjects in the lab 
during each session. Each experimental session proceeded in three parts. Subjects were given instructions, available in the Appendix, at the beginning of each part and the experimenter read the instructions aloud. In the first part subjects made a series of choices in simple lotteries, similar to Holt and Laury (2002). The second and the third parts of the experiment corresponded to two out of four treatments. For example, in GC-UC, each subject played in a grand contest for 30 periods, then played for 30 periods in an unequal prize contest. In each period, subjects were randomly and anonymously placed into a group of 4 players in $\mathrm{GC}, \mathrm{UC}$, and $\mathrm{EC}$ treatments or into a group of 2 players in SC treatment.

Table 3.2 - Summary of Treatments and Sessions

\begin{tabular}{lccccc}
\hline \hline \multirow{2}{*}{ Design } & $\begin{array}{c}\text { Number of } \\
\text { Sessions }\end{array}$ & $\begin{array}{c}\text { Total } \\
\text { Participants }\end{array}$ & $\begin{array}{c}\text { Number of } \\
\text { Decisions }\end{array}$ & $\begin{array}{c}\text { Number of } \\
\text { Periods }\end{array}$ & Endowment \\
\hline GC-UC & 2 & 24 & 1440 & 30 & 60 \\
UC-GC & 2 & 24 & 1440 & 30 & 60 \\
EC-SC & 2 & 24 & 1440 & 30 & 60 \\
SC-EC & 2 & 24 & 1440 & 30 & 60 \\
GC-UC (40) & 1 & 12 & 720 & 30 & 40 \\
Pilot Sessions & 2 & 24 & 960 & 20 & 60 \\
\hline
\end{tabular}

At the beginning of each period, each subject received an endowment of 60 experimental francs. Subjects could use their endowments to expend efforts (place bids) in order to win a prize. Subjects were informed that by increasing their efforts, they would increase their chance of winning the prize and that, regardless of who wins the prize, all subjects would have to pay for their efforts. After all subjects submitted their efforts the computer assigned the winner via a simple lottery. At the end of each period, the sum of all efforts in the group, the result of the random draw, and personal period earnings were reported to all subjects. After completing all 60 decision periods, 10 periods were randomly selected for payment ( 5 periods for each treatment). The earnings were converted into US dollars at the rate of 50 francs to $\$ 1$. On average, subjects 
earned $\$ 18$ each and this was paid in cash. The experimental sessions lasted for about 70 minutes.

\section{Results}

Table 4.1 summarizes average efforts and payoffs over all treatments, and shows that subjects over-expend effort relative to the risk-neutral Nash prediction. As a result, payoffs are lower than expected. Note that on average players competing in the grand contest do not earn any positive payoffs. The dissipation rate is defined as the ratio of the expended total effort (revenue) to the value of the prize. In the grand contest $100 \%$ of the rent is dissipated by 4 players, while only $66 \%$ of the rent is dissipated by 4 players in the two subcontests. Actual dissipation rates are significantly higher than what is predicted by the theory. ${ }^{5}$

Result 1. Significant over-dissipation is observed in all treatments.

Table 4.1 also reports the total revenue collected in each contest. This revenue can be calculated by summing up all efforts within a given contest or by multiplying dissipation rate by the prize value. The data indicates that all four revenues are ranked consistently with the theory. The revenue collected in the EC treatment is higher than the revenue collected in the SC treatment. A random-effect regression of effort on the treatment dummy-variable, session dummy-variables, and a period trend indicates that the revenue difference is significant ( $p$-value $<0.05){ }^{6}$ This finding is consistent with Hypothesis 3 . The actual difference between the revenue

\footnotetext{
${ }^{5}$ To support this conclusion we estimated a simple panel regression for each treatment, where the dependent variable is effort and independent variables are a constant and session dummy-variables. The model included a random effects error structure, with the individual subject as the random effect, to account for the multiple decisions made by individual subjects. Based on a standard Wald test, conducted on estimates of a model, we found that for all treatments the constant coefficients are significantly higher than the predicted theoretical values in Table $4.1(p$ value $<0.05)$. The same conclusion also stands after clustering standard errors at the session level ( $p$-value $<0.05)$.

${ }^{6}$ When clustering standard errors at the session level, the difference is significant only for the last 15 periods of the experiment $(p$-value $<0.05)$.
} 
collected in the EC and SC treatments is about $8(=86-78)$, which is very close to the theoretical prediction of $10(=70-60)$.

Result 2. The equal-prize joint contest generates significantly greater effort and revenue than the two equivalent subcontests.

\section{Table 4.1 - Average Statistics ${ }^{7}$}

\begin{tabular}{|c|c|c|c|c|c|c|c|}
\hline \multirow{2}{*}{ Treatment } & \multicolumn{2}{|c|}{ Effort, $e$} & \multirow{2}{*}{$\begin{array}{c}\text { Revenue, } \\
T R \\
\end{array}$} & \multicolumn{2}{|c|}{ Payoff, $\pi$} & \multicolumn{2}{|c|}{ Dissipation Rate } \\
\hline & Equilibrium & Actual & & Equilibrium & Actual & Equilibrium & Actual \\
\hline $\mathrm{GC}$ & 22.5 & $30.0 \quad(0.5)$ & 120.1 & 7.5 & $0.0 \quad(1.3)$ & 0.75 & 1.00 \\
\hline $\mathrm{UC}$ & 20.0 & $29.3(0.5)$ & 117.4 & 10.0 & $0.7 \quad(0.9)$ & 0.67 & 0.98 \\
\hline $\mathrm{EC}$ & 17.5 & $21.6(0.3)$ & 86.4 & 12.5 & $8.4 \quad(0.7)$ & 0.58 & 0.72 \\
\hline $\mathrm{SC}$ & 15.0 & $19.7 \quad(0.3)$ & 78.6 & 15.0 & $10.3 \quad(0.8)$ & 0.50 & 0.66 \\
\hline
\end{tabular}

Standard error of the mean in parentheses. The total number of observations in each treatment is 1440 .

The next result, which supports Hypothesis 2, is that the revenue collected in the UC treatment exceeds the revenue collected in the EC treatment. Based on the estimation of a random-effect model with standard errors clustered at the session level, the difference in revenues is significant $(p$-value $<0.05)$. Although this finding supports Hypothesis 2, the difference in revenues of $31(=117-86)$ is much higher than the theoretical difference of $10(=80$ 70).

Result 3. The unequal-prize contest generates significantly greater effort and revenue than the equal-prize contest.

The grand contest is designed to produce the highest competition from the contestants and therefore generates the highest revenue for the administrator. Table 4.1 shows that the grand contest indeed generates the highest effort level, the highest revenue, and the highest dissipation rate. This provides support for Hypothesis 1. Based on the estimation of a random-effect model

\footnotetext{
${ }^{7} \mathrm{We}$ also checked for a possible order effect since subjects consecutively played in two of the four possible contests. No significant difference was found. In fact, the averages presented in Table 4.1 are almost identical to the averages when we consider only the first treatment in each session. In GC, UC, EC and SC the average efforts without the order effect are $30.2,29.9,21.5$, and 18.5.
} 
with standard errors clustered at the session level, the effort expended in the GC treatment is significantly higher than the effort expended in the EC treatment $(p$-value $<0.05)$ and the SC treatment $(p$-value $<0.05)$. The difference in effort between the GC and UC treatments is significant only for the last 15 periods of the experiment $(p$-value $<0.05){ }^{8}$

Result 4. The grand contest generates somewhat higher efforts and revenue than unequalprize contest and considerably higher efforts and revenue than either equal-prize contest or two equivalent subcontests.

Overall, Results 2, 3, and 4 provide strong empirical support for the theoretical findings of contest design: the most rent-seeking efforts are obtained when a large prize is provided instead of several small prizes and the joint contest generates higher revenue than a set of subcontests. The support for comparative statics comes from aggregate rather than individual analysis of the data. Figure 4.1a displays the full distribution of efforts made in first 15 periods of the experiment. It is striking to see that, instead of following a unique pure strategy Nash equilibrium, subjects' efforts are distributed on the entire strategy space. In the SC treatment, for example, all efforts should be concentrated at 15 , but instead they range from 0 to 60 . Similar behavior is observed in GC, UC, and EC treatments.

Result 5. The actual efforts are distributed on the entire strategy space.

\footnotetext{
${ }^{8}$ It is important to emphasize that although the average efforts are similar in both GC and UC treatments, the strategic behavior of individual subjects is very different. By analyzing individual efforts, we find that in the GC treatment subjects choose 0 and 60 more often than in the UC treatment (right panel of Figure 4.1b). As a result, there are more subjects who compete too much and at the same time more subjects who drop out of the competition in the GC treatment than in the UC treatment.
} 
Figure 4.1a - Distribution of Efforts in Periods 1-15
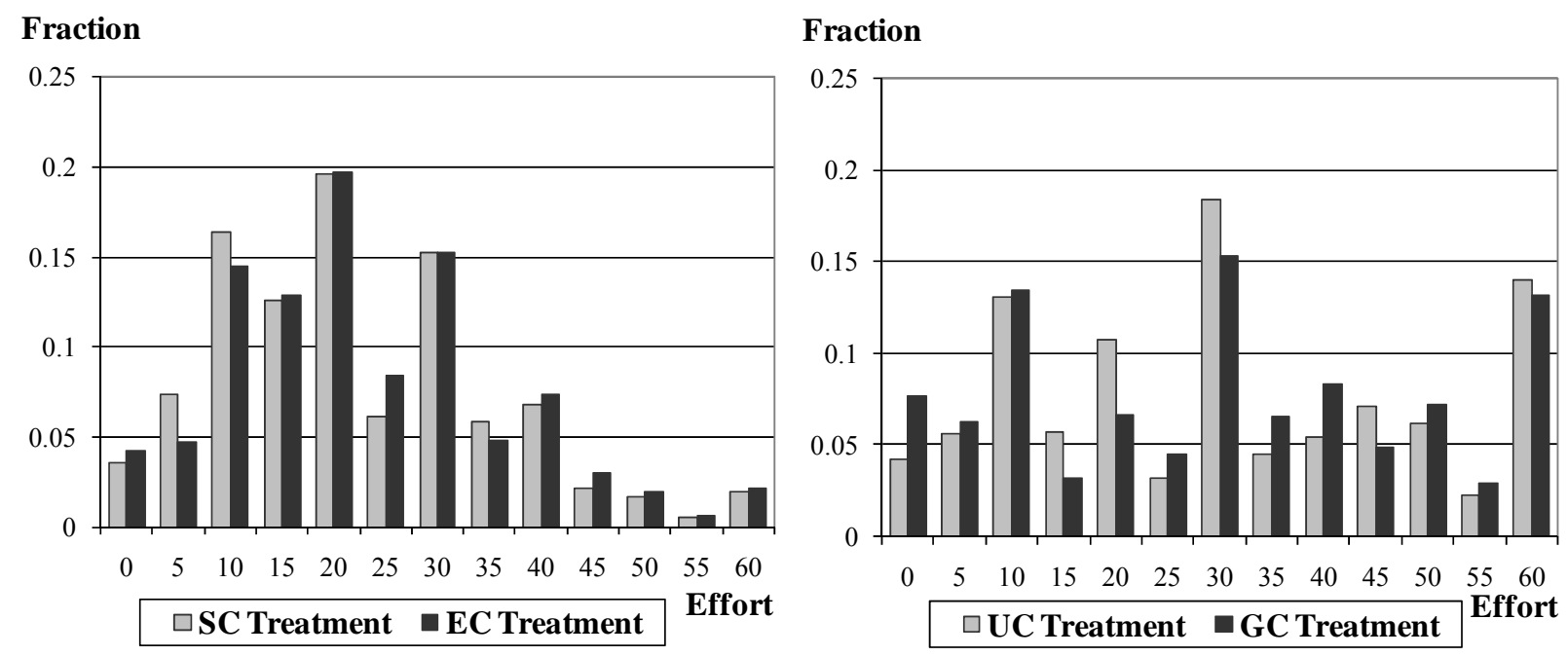

Figure 4.1b - Distribution of Efforts in Periods 16-30
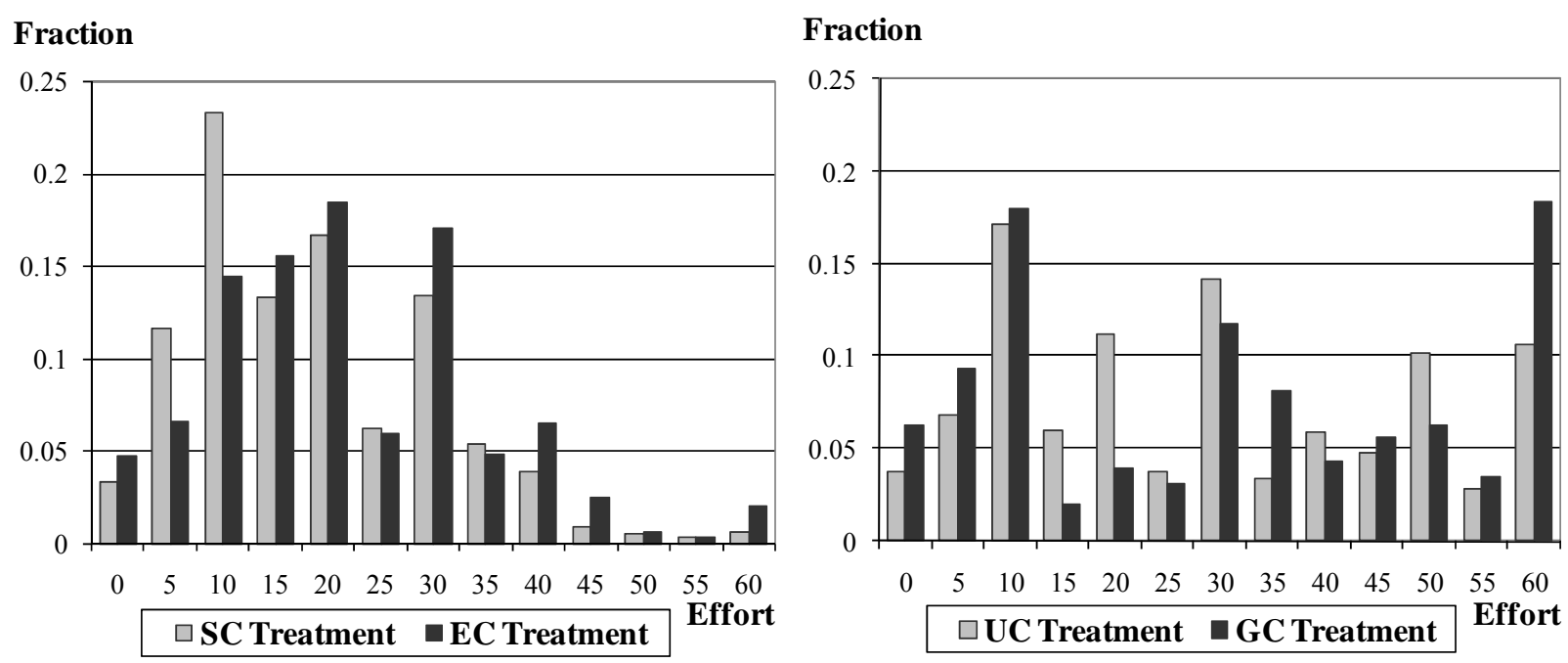

It is often argued that subjects need to get some experience in order to learn how to play the equilibrium (Camerer, 2003). For that reason, Figure 4.1b displays the distribution of efforts in final 15 periods of the experiment. The fraction of the equilibrium efforts in the SC and EC treatments is around $13-16 \%$ and the fraction of equilibrium efforts in the GC and UC treatments is around $4-11 \%$. There is a minor difference between the distribution of efforts in periods $1-15$ and periods 16-30. Nevertheless, some learning takes place. The fraction of efforts which are 
higher than the equilibrium decreases and the fraction of efforts which are lower than the equilibrium increases with the periods played. This can be seen by the leftward shift of distributions in Figure 4.1a versus Figure 4.1b (note that there is no leftward shift in the GC treatment). In Section 5 we provide more formal analysis of the learning trends that occur in our experiment.

Another argument that is commonly made in the experimental and theoretical literature is that players may play an asymmetric equilibrium instead of a symmetric equilibrium (Dechenaux et al., 2006). Although Clark and Riis (1998) do not prove the uniqueness of the pure strategy equilibrium (3), in our specific case the equilibrium is indeed unique (Szidarovszky and Okuguchi, 1997; Cornes and Hartley, 2005). ${ }^{9}$

Figure 4.2 - Average Effort by Subjects in EC-SC and GC-UC Treatments
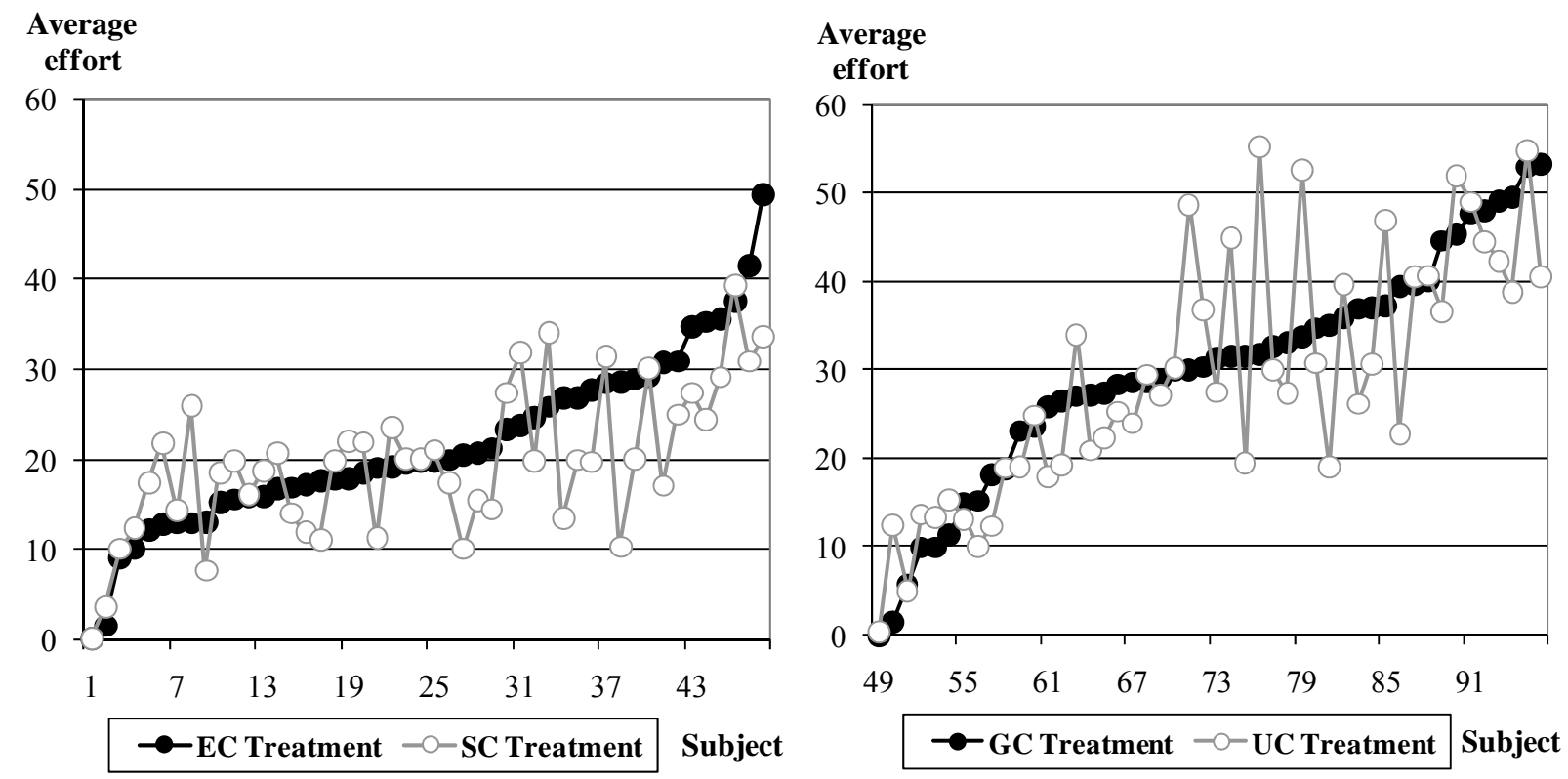

\footnotetext{
${ }^{9}$ Because of experimental design all players are restricted to choose integer effort levels from 0 to 60 . Therefore, one can look at the 4-player contest as 4-dimensional normal form game with nearly 1.4E+07 possible outcomes. We ran computer simulation to check for all possible pure strategy equlibria and the only one that was found is unique and symmetric. Because of the restriction on the strategy space, in the equilibrium of the GC (EC) treatment two players expend 23 (18) francs and two players expend 22 (17) francs. It is also important to emphasize that because of the concavity of payoff functions the pure strategy equilibrium is also the unique mixed strategy equilibrium. We performed computer simulation for the SC treatment to confirm this.
} 
Figure 4.2 displays the average efforts by all subjects who participated in the experiment. On the left side each subject is ranked by the average effort he expended in the EC treatment and on the right side each subject is ranked by the average effort he expended in the GC treatment. Some subjects never enter the competition and expend zero effort in all periods, while others expend substantial effort, averaging about $50 .^{10}$

Result 6. There is a strong heterogeneity in efforts between the subjects.

Uniqueness of the pure strategy equilibrium and findings in Results 1, 5, and 6 produce a challenge for contest theory. Nevertheless, Results 2, 3, and 4 support the major comparative static predictions. Why individual behavior is different across subjects is a separate question. There are many behavioral and demographic factors that may cause these differences. The next section explores in more detail the possible behavioral and demographic factors that cause subjects to deviate from the theoretical predictions.

\section{Exploring Over-Dissipation}

\subsection{Quantal Response Equilibrium}

Although the comparative statics predictions hold in the experiment, there is a significant over-dissipation in all treatments (Result 1) which is not captured by the theory. Potters et al. (1998) conjectured that most subjects are likely to make mistakes. These mistakes add noise to the Nash equilibrium solution and thus may cause over-dissipation in contest games. We check this hypothesis by applying a quantal response equilibrium (QRE) developed by McKelvey and

\footnotetext{
${ }^{10}$ Evidently, the participants who bid more in the EC treatment are also more likely to bid more in the SC treatment. We can track this correlation since each subject participated in two different treatments in each session. The Spearman's rank correlation coefficient, $\rho$, is 0.58 and it is significantly greater than zero ( $p$-value $<0.05)$. The correlation between the GC and UC treatment is even higher, $\rho=0.81$ ( $p$-value $<0.05)$. This important observation shows the consistency of each subject's behavior across different experimental contests. Therefore, it strongly confirms the presence of heterogeneity between the subjects.
} 
Palfrey (1995). The crucial parameter of this model is the error parameter, $\mu$, which determines the sensitivity of the choice probabilities with respect to payoffs. The maximum likelihood estimates of $\mu$ for each treatment are shown in the Table 5.1. ${ }^{11}$ The table also reports the corresponding value of the likelihood function. The level of mistakes made in the GC and UC treatments is very high. We cannot reject the random play hypothesis for either of the treatments. This conclusion stands even when we estimate the model based on the data from the last 15 periods of the experiment. On the other hand, the behavior in the EC and SC treatments can be captured by the QRE with a reasonable level of mistakes.

Table 5.1 - QRE Computation Based on All Periods

\begin{tabular}{ccccc}
\hline \hline Treatment & $\mu$, error & LL & $\begin{array}{c}\text { LR test } \\
\text { (Random) }\end{array}$ & $\begin{array}{c}\text { LR test } \\
\text { (Equilibrium) }\end{array}$ \\
\hline GC & $1.21 \mathrm{E}+07$ & -5919.7 & $p=0.99$ & $p<0.01$ \\
UC & 729.4 & -5919.7 & $p=0.77$ & $p<0.01$ \\
EC & 9.3 & -5654.6 & $p<0.01$ & $p<0.01$ \\
SC & 9.3 & -5557.9 & $p<0.01$ & $p<0.01$ \\
GC (40) & 113.4 & -1336.7 & $p=0.56$ & $p<0.01$ \\
UC (40) & 3.2 & -1274.5 & $p<0.01$ & $p<0.01$ \\
\hline
\end{tabular}

Figure 5.1 illustrates the average effort at the QRE as a function of $\mu$ for each treatment. On the vertical axis we find the average effort for each player. When $\mu$ is zero, the behavior is consistent with the Nash equilibrium. With increasing level of mistakes, all players over-expend average effort relative to the Nash equilibrium. As players move closer to random play, i.e., putting equal weights on each strategy, the average effort approaches 30 (one half of the endowment). Even without additional computation one can see how the QRE can account for the over-dissipation in all treatments of the experiment. For example, the average effort of 19.6 in the SC treatment falls perfectly on the bottom curve around $\mu \approx 9$ (left panel of Figure 5.1).

\footnotetext{
${ }^{11}$ The estimation procedure followed Goeree et al. (2002). A more detail description of the estimation procedure is available from the author upon a request.
} 
It is important to emphasize that computation of QRE is heavily dependent on the initial endowment which subjects receive to play the contest game. In our experiment, each period all subjects receive an endowment of 60 . Given this endowment, according to the QRE, at each level of mistakes subjects can only expend effort which is higher than the Nash equilibrium (left panel of Figure 5.1). Therefore, one may argue that the over-dissipation in contests can always be explained by the QRE. ${ }^{12}$ However, this argument is not necessarily true because lower endowments may lead to under-dissipation relative to the Nash equilibrium prediction. For example, when the endowment is 40, the QRE predicts that higher level of mistakes in the GC treatment should result in under-dissipation (right panel of Figure 5.1). The intuition behind this prediction is straightforward: when subjects have large endowments then their mistakes are more likely to result in over-dissipation, while small endowments are more likely to result in underdissipation.

\section{Figure 5.1 - Average Effort at the QRE}
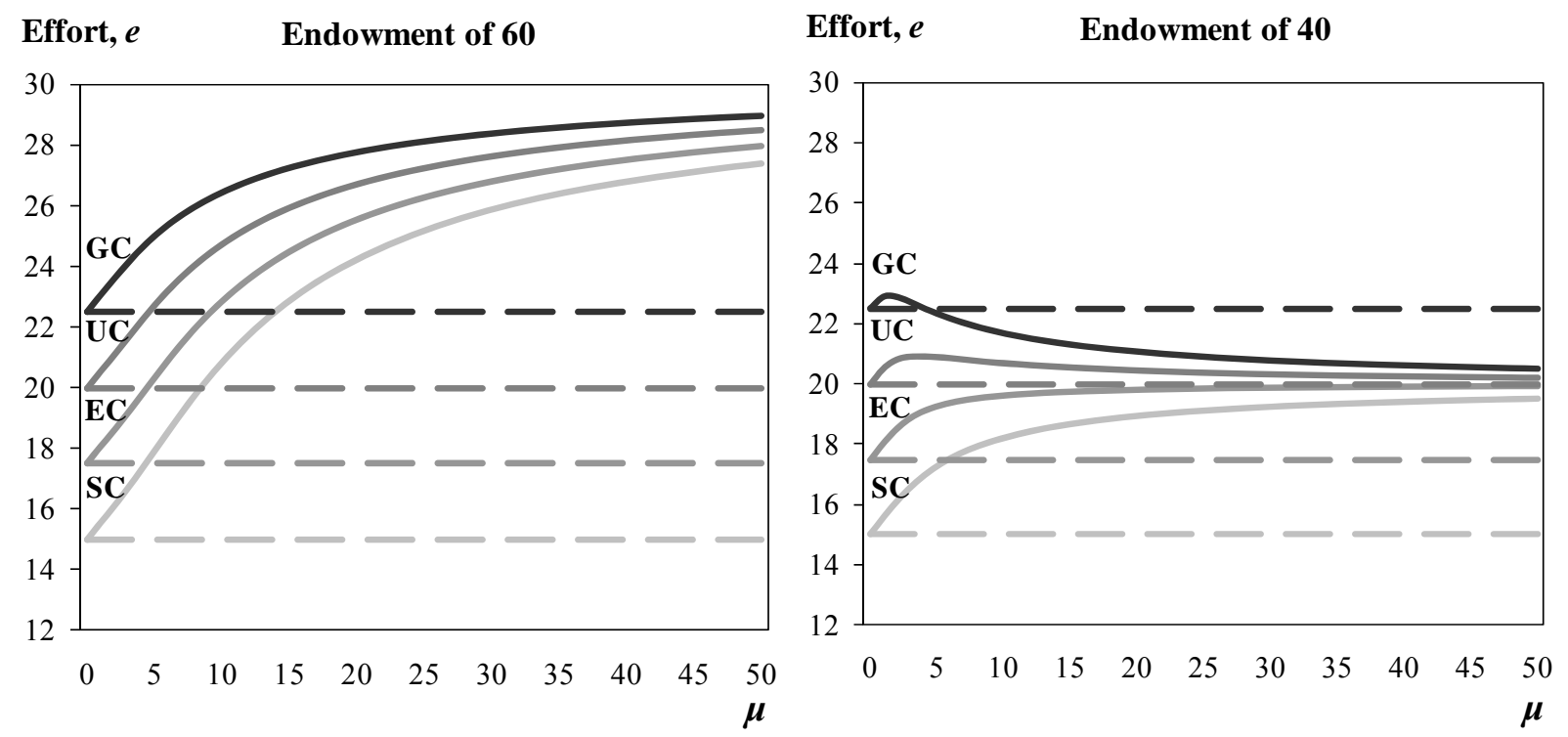

\footnotetext{
12 Bullock and Rutstrom (2007) find that observed behavior in the Tullock-type model of political competition is fully captured by QRE predictions. Anderson et al. (1998) develop a theoretical model of the all-pay auction based on the QRE. The model predicts that overbidding in the all-pay auction occurs due to the mistakes and that overbidding should increase with the size of the bidders' group. Nevertheless, Gneezy and Smorodinsky (2006) found that the over-dissipation in the all-pay auction is independent of the group size in later periods.
} 
To make a definite conclusion, we conducted one more session with GC (40) and UC (40) treatments. This time each subject was given an endowment of 40 instead of 60 . We were very surprised to discover that the average effort in GC (40) treatment indeed fell from 30.0 to 21.6 which is below the Nash equilibrium prediction of 22.5. In the UC (40) treatment, average effort fell from 29.3 to 21 . This finding is a strong support for QRE. ${ }^{13}$ It is also consistent with Sheremeta (2008), who conducted one treatment equivalent to the GC treatment. In that study subjects were given the endowment of 120 francs instead of 60 and as a result the average effort was 34.1 instead of 30. A strong effect of the endowment on subjects' behavior can explain why some experimental studies (Schmidt et al., 2005; Shupp, 2004) find less rent-seeking expenditures than what is predicted by the equilibrium. ${ }^{14}$

\subsection{Risk Aversion}

The QRE model can account for the general trend of over-dissipation in the experiment. However, it cannot explain the heterogeneity in efforts between the subjects (Result 6). In the experimental literature it is believed that this heterogeneity is mainly caused by heterogeneity of risk preferences. Previous experimental studies found a significant effect of risk aversion on the dissipation rate (Miller and Pratt, 1991). In our experiment, rather than estimating risk aversion from the observed choices in contest games (Goeree et al., 2002; Schmidt et al., 2005), in the first stage we used a simple lottery to elicit risk aversion from the subjects.

\footnotetext{
${ }^{13}$ With the restriction on the endowment, the estimated level of mistakes, $\mu$, also decreased in both treatments (Table 5.1). However, in the GC (40) treatment we still cannot reject the random play hypothesis.

${ }^{14}$ In Schmidt et al. (2005) and Shupp (2004) subjects were given a budget which allowed them to bid up to \$20 while $\$ 13.5$ was the Nash equilibrium prediction. Assuming a substantial level of mistakes made by subjects, the QRE approaches $\$ 10$ and is below the Nash equilibrium. Therefore, taking into account our findings about the effect of the endowment on the behavior of the rent-seekers, we can explain why these authors find significant under dissipation in their experiments.
} 


\section{Table 5.2 - Classification of Subjects by Risk Aversion (All Treatments)}

\begin{tabular}{cccc}
\hline \hline $\begin{array}{c}\text { Number of } \\
\text { A choices }\end{array}$ & $\begin{array}{c}\text { Number of } \\
\text { Subjects }\end{array}$ & $\begin{array}{c}\text { Relative Risk } \\
\text { Aversion, } r\end{array}$ & $\begin{array}{c}\text { Average } \\
\text { Effort, } e\end{array}$ \\
\hline 4 & 1 & 1.73 & 30.07 \\
5 & 2 & 1.46 & 33.03 \\
6 & 4 & 1.26 & 34.94 \\
7 & 18 & 1.10 & 25.68 \\
8 & 12 & 0.96 & 24.74 \\
9 & 10 & 0.83 & 27.06 \\
10 & 19 & 0.73 & 21.86 \\
11 & 14 & 0.63 & 26.59 \\
12 & 8 & 0.54 & 22.93 \\
13 & 5 & 0.46 & 25.11 \\
14 & 1 & 0.39 & 9.55 \\
15 & 2 & 0.32 & 10.07 \\
\hline
\end{tabular}

Following Holt and Laury (2002), subjects were asked to state whether they preferred safe option A or risky option B. In the experiment, the majority of subjects chose the safe option A when the probability of the high payoff in option B was small, and then crossed over to option B. ${ }^{15}$ Table 5.2 presents a summary of A choices made by all subjects in the experiment. Risk neutrality corresponds to the switching point of either 7 or 8 safe choices A. The majority of subjects show a tendency toward risk-averse behavior. Based on the observed switching point for each subject, we can estimate their degree of risk aversion. ${ }^{16}$ To be consistent with other studies we calculate risk aversion parameters, $r$, based on the assumption that all subjects have constant relative risk aversion. The estimates are shown in Table 5.2. Higher $r$ corresponds to lower number of safe choices A. Conventionally, subjects are considered to be risk-seeking when $r>1$.

\footnotetext{
${ }^{15}$ Option A yielded $\$ 1$ payoff with certainty, while option B yielded a payoff of either $\$ 3$ or $\$ 0$. The probability of receiving $\$ 3$ or $\$ 0$ varied across all 15 lotteries. The first lottery offered a 5\% chance of winning $\$ 3$ and a $95 \%$ chance of winning $\$ 0$, while the last lottery offered a $70 \%$ chance of winning $\$ 3$ and a $30 \%$ chance of winning $\$ 0$.

${ }^{16}$ Note that switching from A to B only gives us an interval of risk aversion coefficient. However, for statistical computations we will use a mid-point approximation.
} 
Risk neutrality corresponds to the case when $r=1$. As $r$ decreases, subjects become more riskaverse and prefer more safe options A.

Theoretical work by Hillman and Katz (1984) showed that risk-averse players should exert lower efforts than the prediction for risk-neutral players and risk-seeking players should exert higher efforts. Thus, if risk aversion is a crucial factor for explaining heterogeneity between the subjects then the efforts expended in the contest should be negatively correlated with the number of safe choices made. The last column of Table 5.2 displays an average effort corresponding to the number of safe choices A made by all subjects. Consistent with the theory, there is significant negative correlation between these two variables. The Spearman's rank correlation coefficient, $\rho$, is -0.81 and it is significantly different from zero $(p$-value $<0.05)$.

\subsection{Lag Dependence and Assessment of the Random Draw}

So far, we have discussed several explanations for over-dissipation (Result 1) and heterogeneity between the subjects (Result 6). Another question that needs to be addressed is why actual efforts are distributed on the entire strategy space (Result 5). One explanation may come from the probabilistic nature of lottery contests. The random draw made by the computer in period $t$-1 may affect the individual behavior in period $t$. To capture this dynamic we estimated several random-effect (RE) models as in Table 5.3. In the estimation we used the data only from the 8 main sessions. The estimation results were very similar when sing the data from all 11 sessions. 
Table 5.3 - Random-Effect Models

\begin{tabular}{|c|c|c|c|}
\hline \multirow{2}{*}{ Dependent variable, Effort } & (1) & (2) & (3) \\
\hline & RE & RE & $\mathrm{RE}$ \\
\hline$\overline{\text { risk aversion }}$ & $-1.34 * * *$ & $-1.28 * * *$ & $-0.83 * * *$ \\
\hline [\# of safe options A] & $(0.30)$ & $(0.21)$ & $(0.09)$ \\
\hline inconsistency & 0.85 & 0.7 & 0.18 \\
\hline \multirow{2}{*}{$\begin{array}{l}\text { [1 if subject is inconsistent in the lottery choices] } \\
\text { bidding time }\end{array}$} & $(2.37)$ & $(1.62)$ & $(0.71)$ \\
\hline & $0.09 * *$ & $0.11^{* *}$ & $0.14 * * *$ \\
\hline [time spent to make a decision] & $(0.04)$ & $(0.04)$ & $(0.04)$ \\
\hline time trend & $5.06 * * *$ & $4.68 * * *$ & $4.59^{* *}$ \\
\hline [inverse of a time trend $1 / t]$ & $(1.68)$ & $(1.68)$ & $(1.78)$ \\
\hline quiz & -0.80 & $-0.67 *$ & $-0.57 * * *$ \\
\hline [\# correct quiz answers] & $(0.56)$ & $(0.38)$ & $(0.17)$ \\
\hline win-lag & $2.17^{* * *}$ & & \\
\hline$[1$ if subject won in $t-1]$ & $(0.36)$ & & \\
\hline \multicolumn{2}{|l|}{ fairwin-lag } & $5.57 * * *$ & $2.00^{* * *}$ \\
\hline \multicolumn{2}{|l|}{ [ 1 if subject wins in period $t-1$ and the draw is fair] } & $(0.41)$ & $(0.50)$ \\
\hline \multicolumn{2}{|l|}{ unfairwin-lag } & $-3.11 * * *$ & $-2.61 * * *$ \\
\hline \multicolumn{2}{|l|}{ [ 1 if subject wins in period $t-1$ and the draw is unfair] } & $(0.54)$ & $(0.56)$ \\
\hline \multicolumn{2}{|l|}{ daverage-lag } & & $0.51 * * *$ \\
\hline \multicolumn{2}{|l|}{ [deviation from average effort in $t-1$ ] } & & $(0.02)$ \\
\hline \multirow{2}{*}{ treatment-GC } & $17.34 * * *$ & $5.16^{* * *}$ & $18.56^{* * *}$ \\
\hline & $(2.48)$ & $(1.71)$ & $(0.82)$ \\
\hline treatment-UC & $16.01 * * *$ & $3.85 * *$ & $17.71 * * *$ \\
\hline$[1$ if treatment is $\mathrm{UC}]$ & $(2.48)$ & $(1.71)$ & $(0.81)$ \\
\hline treatment-EC & $2.06^{* * *}$ & $2.05^{* * *}$ & $2.07 * * *$ \\
\hline [1 if treatment is EC] & $(0.48)$ & $(0.48)$ & $(0.51)$ \\
\hline \multirow[t]{2}{*}{ constant } & $35.51 * * *$ & $34.08 * * *$ & $28.14 * * *$ \\
\hline & $(5.28)$ & $(3.62)$ & $(1.78)$ \\
\hline Observations & 5568 & 5568 & 5568 \\
\hline
\end{tabular}

Specification (1) is a simple RE regression of individual efforts made in all periods of the experiment on experimentally relevant explanatory variables. The coefficient capturing risk aversion is significant and has the expected sign. The variable inconsistency is intended to capture the subjects who demonstrated inconsistency in their risk preferences. Time spent on making a decision has a positive effect on over-dissipation. One explanation for this may be that subjects who take more time to make their decisions are actually confused about what they should do and therefore they make more mistakes (from section 5.1, more mistakes corresponds 
to higher over-dissipation). We also find that the inverse of a time trend is positive and significant which suggests that individual learning is taking place and, that with the repetition of the game, subjects expend lower efforts. The quiz variable is measured by the number of correct quiz answers (a measure of how well subjects understand the instructions) and is designed to capture the ability factor. ${ }^{17}$ Specifications (2) and (3) indicate that subjects who understand the instructions better expend significantly lower efforts in contests. Therefore, this is another evidence that the over-dissipation is caused by subjects who make mistakes and who do not understand the game.

To capture the dynamics of the game we include a win-lag variable. This is a dummyvariable which takes on the value of 1 if the player won the prize in period $t-1$ and is 0 otherwise. In specification (1), this variable has a significant positive effect on effort. One explanation for this finding is due to the income effect: subjects who won in period $t$-1 have higher income in period $t$ and therefore expend higher efforts. ${ }^{18}$ In specification (2), instead of using win-lag variable, we use fairwin-lag and unfairwin-lag variables. The fairwin-lag (unfairwin-lag) variable takes on the value of 1 if subject wins the prize in period $t-1$ and the random draw in period $t-1$ is fair (unfair). The fair draw is defined as a random draw that favors the player whose effort is higher than the average effort in the group. On the other hand, the unfair draw favors a player with a low effort. From the estimation, we find that the subjects who expend high efforts and win raise their efforts in the consecutive period, while the subjects who expend low efforts and win reduce their efforts in the consecutive period. One may argue that this is simply due to

\footnotetext{
${ }^{17}$ Before the actual experiment, subjects completed the quiz on the computer to verify their understanding of the instructions. If a subject's answer was incorrect, the computer provided the correct answer. The experiment started only after all participants had answered all quiz questions.

${ }^{18}$ It is rather surprising since we tried to avoid this effect by using random payment. It is also possible that subjects derive utility from winning (Goeree et al., 2002; Sheremeta, 2008). Thus, subjects who win the prize in period $t$ - 1 expend higher efforts to ensure that they win the prize in period $t$.
} 
the fact that subjects who expend higher (lower) efforts in one period are also more likely to expend higher (lower) efforts in the next period. To address this argument we run specification (3) in which we include daverage-lag variable. This variable is equal to the difference between player $i$ 's effort and the average effort in the group in period $t$-1. From the estimation we find that this variable is indeed significant, i.e., subjects whose efforts are above the average in the past exert higher efforts in the current period. Even though the magnitudes of fairwin-lag and unfairwin-lag variables dropped, both variables are still significant. The response to fair and unfair draw by the subjects is intuitive but it is not rational. Since the nature of winning the contest is probabilistic, the perception of fair and unfair draw is important in explaining why subjects vary their efforts across periods and why actual efforts are distributed on the entire strategy space.

\section{Conclusions}

In this study we use experimental methods to test several theoretical predictions of contest design literature. We investigate and compare the performance of four simultaneous contests: a grand contest, two multi-prize settings (equal and unequal prizes), and a contest which consists of two subcontests. Consistent with the theory, we find that the grand contest generates the highest revenue among all simultaneous contests. We also find that in multi-prize settings, equal prizes produce lower efforts than unequal prizes. Finally, our experiment supports

the argument that joint contests generate higher efforts than the equivalent number of subcontests.

Although the comparative statics predictions hold in our experiment, consistent with the other experimental studies, there is a strong heterogeneity between the subjects and significant 
over-dissipation of rent (Millner and Pratt, 1989, 1991; Davis and Reilly, 1998; Potters et al., 1998). Subjects' heterogeneity can be explained to some extent by differences in risk preferences. Significant over-dissipation can be partially explained by strong endowment size effects.

We argue that because of the probabilistic nature of lottery contests it is important to control for lag of winning and misperception of the random draw. Subjects who expend high efforts and win the prize in period $t$ - 1 raise their efforts in the consecutive period, while subjects who expend low efforts and win in period $t-1$ substantially decreased their efforts in period $t$. These findings are attributed to the misperception of the random draw and they can partly explain why actual efforts in contests are distributed on the entire strategy space. 


\section{References}

Amegashie, J.A. (2000). Some Results on Rent-Seeking Contests with Shortlisting. Public Choice, 105, 245-253.

Anderson, S.P., Goeree, J.K., \& Holt, C.A. (1998). Rent Seeking with Bounded Rationality: An Analysis of the All-Pay Auction, Journal of Political Economy, 106, 828-853.

Baik, K.H., \& Lee, S. (2000). Two-Stage Rent-Seeking Contests with Carryovers. Public Choice, $103,285-296$.

Barut, Y., \& Kovenock, D. (1998). The Symmetric Multiple Prize All-Pay Auction with Complete Information. European Journal of Political Economy, 14, 627-644.

Bullock, D., \& Rutström, E. (2007). Policy making and rent-dissipation: An experimental test, Experimental Economics, 10, 21-36.

Che, Y.K., \& Gale, I. (2003). Optimal Design of Research Contests. American Economic Review, 93, 646-671.

Clark, D.J., \& Riis, C. (1998). Influence and the Discretionary Allocation of Several Prizes. European Journal of Political Economy, 14, 605-625.

Cornes, R., \& Hartley, R. (2005). Asymmetric Contests with General Technologies. Economic Theory, 26, 923-946.

Davis, D., \& Reilly, R. (1998). Do Many Cooks Always Spoil the Stew? An experimental analysis of rent seeking and the role of a strategic buyer. Public Choice, 95, 89-115.

Dechenaux, E., Kovenock, D., \& Lugovskyy, V. (2006). Caps on Bidding in All-Pay Auctions: Comments on the Experiments of A. Rapoport and W. Amaldoss. Journal of Economic Behavior and Organization, 61, 276-283.

Fischbacher, U. (2007). z-Tree: Zurich Toolbox for Ready-made Economic experiments, Experimental Economics, 10, 171-178.

$\mathrm{Fu}, \mathrm{Q} .$, \& $\mathrm{Lu}, \mathrm{J}$. (2007). The optimal multi-stage contest. University of Munich, Working Paper.

Fu, Q., \& Lu, J. (2009). The Beauty of "Bigness": on Optimal Design of Multi Winner Contests. Games and Economic Behavior, forthcoming.

Galton, F. (1902). The Most Suitable Proportion Between The Values Of First And Second Prizes, Biometrika, 1, 385-390.

Glazer, A., \& Hassin, R. (1988). Optimal contests. Economic Inquiry, 26, 133-143.

Gneezy, U., \& Smorodinsky, R. (2006). All-Pay Auctions - An Experimental Study, Journal of Economic Behavior and Organization, 61, 255-275.

Goeree, J., Holt, C., \& Palfrey, T. (2002). Quantal Response Equilibrium and Overbidding in Private-Value Auctions. Journal of Economic Theory, 247-272.

Gradstein, M., \& Konrad, K.A. (1999). Orchestrating Rent Seeking Contests. Economic Journal, $109,536-45$.

Harbring, C., \& Irlenbusch, B., (2003). An Experimental Study on Tournament Design, Labour Economics, 10, 443-464.

Harbring, C., \& Irlenbusch, B., (2005). Incentives in Tournaments with Endogenous Prize Selection, Journal of Institutional and Theoretical Economics, 127, 636-663.

Harbring, C., Irlenbusch, B. Krakel, M., \& Selten, R. (2007). Sabotage in Corporate Contests An Experimental Analysis. International Journal of the Economics of Business, 14, 367-392.

Hillman, A.L., \& Katz, E. (1984). Risk-Averse Rent Seekers and the Social Cost of Monopoly Power. Economic Journal, 94, 104-110.

Holt, C.A., \& Laury, S.K. (2002). Risk Aversion and Incentive Effects. American Economic Review, 92, 1644-55. 
Kräkel, M. (2006). Splitting Leagues, Journal of Economics, 88, 21-48.

Krueger, A.O. (1974). The Political Economy of the Rent-Seeking Society. American Economic Review, 64, 291-303.

Lange, A., List, J.A., \& Price, M.K., (2007). Using Lotteries to Finance Public Goods: Theory and Experimental Evidence. International Economic Review, 48, 901-927.

Lazear, E.P., \& Rosen, S. (1981). Rank-Order Tournaments as Optimum Labor Contracts. Journal of Political Economy, 89, 841-864.

Lynch, J., \& Zax, J. (2000). The Rewards to Running: Prize Structure and Performance in Professional Road Racing, Journal of Sports Economics, 1, 323-340.

Maloney, M.T., \& McCormick, R.E. (2000). The Response of Workers to Wages in Tournaments: Evidence From Foot Races, Journal of Sports Economics, 1, 99-123

McKelvey, R., \& Palfrey, T. (1995). Quantal Response Equilibria for Normal Form Games. Games and Economic Behavior, 10, 6-38.

Millner, E.L., \& Pratt, M.D. (1989). An experimental investigation of efficient rent-seeking. Public Choice, 62, 139-151.

Millner, E.L., \& Pratt, M.D. (1991). Risk Aversion and Rent-Seeking: An Extension and Some Experimental Evidence, Public Choice, 69, 81-92.

Moldovanu, B., \& Sela, A. (2001). The Optimal Allocation of Prizes in Contests. American Economic Review, 91, 542-558.

Moldovanu, B., \& Sela, A. (2006). Contest architecture. Journal of Economic Theory, 126, 7096.

Morgan, J., \& Sefton, M. (2000). Funding Public Goods with Lotteries: Experimental Evidence. Review of Economic Studies, 67, 785-810.

Müller, W., \& Schotter, A., (2007). Workaholics and Drop outs in Optimal Organizations. Working Paper, New York University.

Orrison, A., Schotter, A., \& Weigelt, K. (2004). Multiperson Tournaments: An Experimental Examination. Management Science, 50, 268-79.

Potters, J.C., De Vries, C.G., \& Van Linden, F. (1998). An Experimental Examination of Rational Rent Seeking. European Journal of Political Economy, 14, 783-800.

Schmidt, D., Shupp, R., \& Walker, J. (2005). Resource Allocation Contests: Experimental Evidence. Indiana University, Working Paper.

Sheremeta, R.M. (2008). Experimental Comparison of Multi-Stage and One-Stage Contests, Purdue University, Working Paper.

Sheremeta, R.M. (2009). Perfect-Substitutes, Best-Shot, and Weakest-Link Contests between Groups, Purdue University, Working Paper.

Shupp, R. (2000). Single versus Multiple Winner Probabilistic Contests: An Experimental Investigation, Ball State University, Working Paper.

Szidarovszky, F., \& Okuguchi, K. (1997). On the Existence and Uniqueness of Pure Nash Equilibrium in Rent-Seeking Games. Games and Economic Behavior, 18, 135-140.

Szymanski, S. (2003). The Economic Design of Sporting Contests, Journal of Economic Literature, 41, 1137-1187.

Szymanski, S., \& Valletti, T.M. (2005). Incentive Effects of Second Prizes, European Journal of Political Economy, 21, 467-481.

Tullock, G. (1980). Efficient Rent Seeking. In James M. Buchanan, Robert D. Tollison, Gordon Tullock, (Eds.), Toward a theory of the rent-seeking society. College Station, TX: Texas A\&M University Press, pp. 97-112. 


\section{Appendix}

\section{GENERAL INSTRUCTIONS}

This is an experiment in the economics of strategic decision making. Various research agencies have provided funds for this research. The instructions are simple. If you follow them closely and make appropriate decisions, you can earn an appreciable amount of money.

The experiment will proceed in three parts. Each part contains decision problems that require you to make a series of economic choices which determine your total earnings. The currency used in Part 1 of the experiment is U.S. Dollars. The currency used in Part 2 and 3 of the experiment is francs. Francs will be converted to U.S. Dollars at a rate of $\mathbf{5 0}$ francs to 1 d dollar. At the end of today's experiment, you will be paid in private and in cash. 12 participants are in today's experiment.

It is very important that you remain silent and do not look at other people's work. If you have any questions, or need assistance of any kind, please raise your hand and an experimenter will come to you. If you talk, laugh, exclaim out loud, etc., you will be asked to leave and you will not be paid. We expect and appreciate your cooperation.

At this time we proceed to Part 1 of the experiment.

\section{INSTRUCTIONS FOR PART 1}

\section{YOUR DECISION}

In this part of the experiment you will be asked to make a series of choices in decision problems. How much you receive will depend partly on chance and partly on the choices you make. The decision problems are not designed to test you. What we want to know is what choices you would make in them. The only right answer is what you really would choose.

For each line in the table in the next page, please state whether you prefer option A or option B. Notice that there are a total of $\mathbf{1 5}$ lines in the table but just one line will be randomly selected for payment. You ignore which line will be paid when you make your choices. Hence you should pay attention to the choice you make in every line. After you have completed all your choices a token will be randomly drawn out of a bingo cage containing tokens numbered from 1 to 15. The token number determines which line is going to be paid.

Your earnings for the selected line depend on which option you chose: If you chose option A in that line, you will receive $\mathbf{\$ 1}$. If you chose option B in that line, you will receive either $\mathbf{\$ 3}$ or $\mathbf{\$ 0}$. To determine your earnings in the case you chose option B there will be second random draw. A token will be randomly drawn out of the bingo cage now containing twenty tokens numbered from 1 to 20. The token number is then compared with the numbers in the line selected (see the table). If the token number shows up in the left column you earn $\$ 3$. If the token number shows up in the right column you earn $\$ 0$.

\section{Any questions?}


Participant ID

\begin{tabular}{|c|c|c|c|c|}
\hline $\begin{array}{l}\text { Decis } \\
\text { ion } \\
\text { no. }\end{array}$ & $\begin{array}{c}\text { Optio } \\
\text { n A }\end{array}$ & & $\begin{array}{l}\text { Option } \\
\text { B }\end{array}$ & $\begin{array}{l}\text { Please } \\
\text { choose } \\
\mathrm{A} \text { or } \mathrm{B}\end{array}$ \\
\hline 1 & $\$ 1$ & \$3 never & $\begin{array}{l}\text { \$0 if } 1,2,3,4,5,6,7,8,9,10,11,12,13 \text {, } \\
14,15,16,17,18,19,20\end{array}$ & \\
\hline 2 & $\$ 1$ & $\begin{array}{l}\$ 3 \text { if } 1 \text { comes out of the bingo } \\
\text { cage }\end{array}$ & $\begin{array}{l}\text { \$0 if } 2,3,4,5,6,7,8,9,10,11,12,13,14,15 \text {, } \\
16,17,18,19,20\end{array}$ & \\
\hline 3 & $\$ 1$ & $\$ 3$ if 1 or 2 comes out & $\begin{array}{l}\text { \$0 if } 3,4,5,6,7,8,9,10,11,12,13,14,15 \text {, } \\
16,17,18,19,20\end{array}$ & \\
\hline 4 & $\$ 1$ & $\$ 3$ if 1,2 or 3 & $\begin{array}{l}\text { \$0 if } 4,5,6,7,8,9,10,11,12,13,14,15 \text {, } \\
16,17,18,19,20\end{array}$ & \\
\hline 5 & $\$ 1$ & $\$ 3$ if $1,2,3,4$ & $\begin{array}{l}\text { \$0 if } 5,6,7,8,9,10,11,12,13,14,15 \text {, } \\
16,17,18,19,20\end{array}$ & \\
\hline 6 & $\$ 1$ & $\$ 3$ if $1,2,3,4,5$ & $\begin{array}{l}\mathbf{\$ 0} \text { if } 6,7,8,9,10,11,12,13,14,15, \\
16,17,18,19,20\end{array}$ & \\
\hline 7 & $\$ 1$ & $\$ 3$ if $1,2,3,4,5,6$ & $\begin{array}{l}\text { \$0 if } 7,8,9,10,11,12,13,14,15, \\
16,17,18,19,20\end{array}$ & \\
\hline 8 & $\$ 1$ & $\$ 3$ if $1,2,3,4,5,6,7$ & $\begin{array}{l}\text { \$0 if } 8,9,10,11,12,13,14,15 \\
16,17,18,19,20\end{array}$ & \\
\hline 9 & $\$ 1$ & $\$ 3$ if $1,2,3,4,5,6,7,8$ & $\begin{array}{l}\text { \$0 } \\
\text { if } 9,10,11,12,13,14,15 \\
16,17,18,19,20\end{array}$ & \\
\hline 10 & $\$ 1$ & $\$ 3$ if $1,2,3,4,5,6,7,8,9$ & $\mathbf{\$ 0}$ if $10,11,12,13,14,15,16,17,18,19,20$ & \\
\hline 11 & $\$ 1$ & $\mathbf{\$ 3}$ if $1,2,3,4,5,6,7,8,9,10$ & $\mathbf{\$ 0}$ if $11,12,13,14,15,16,17,18,19,20$ & \\
\hline 12 & $\$ 1$ & $\$ 3$ if $1,2,3,4,5,6,7,8,9,10,11$ & $\mathbf{\$ 0}$ if $12,13,14,15,16,17,18,19,20$ & \\
\hline 13 & $\$ 1$ & $\$ 3$ if $1,2,3,4,5,6,7,8,9,10,11,12$ & $\$ 0$ if $13,14,15,16,17,18,19,20$ & \\
\hline 14 & $\$ 1$ & $\begin{array}{l}\text { \$3 if } 1,2,3,4,5,6,7,8,9,10 \\
11,12,13\end{array}$ & $\mathbf{\$ 0}$ if $14,15,16,17,18,19,20$ & \\
\hline 15 & $\$ 1$ & $\begin{array}{l}\text { \$3 if } 1,2,3,4,5,6,7,8,9,10 \\
11,12,13,14\end{array}$ & \$0 if $15,16,17,18,19,20$ & \\
\hline
\end{tabular}




\section{INSTRUCTIONS FOR PART 2}

\section{YOUR DECISION}

The second part of the experiment consists of $\mathbf{3 0}$ decision-making periods. At the beginning of each period, you will be randomly and anonymously placed into a group of $\mathbf{4}$ participants. The composition of your group will be changed randomly every period. Each period, you and all other participants will be given an initial endowment of $\mathbf{6 0}$ francs. You will use this endowment to bid for a reward. The reward is worth $\mathbf{1 2 0}$ francs to you and the other three participants in your group. You may bid any integer number of francs between $\mathbf{0}$ and $\mathbf{6 0}$. An example of your decision screen is shown below.

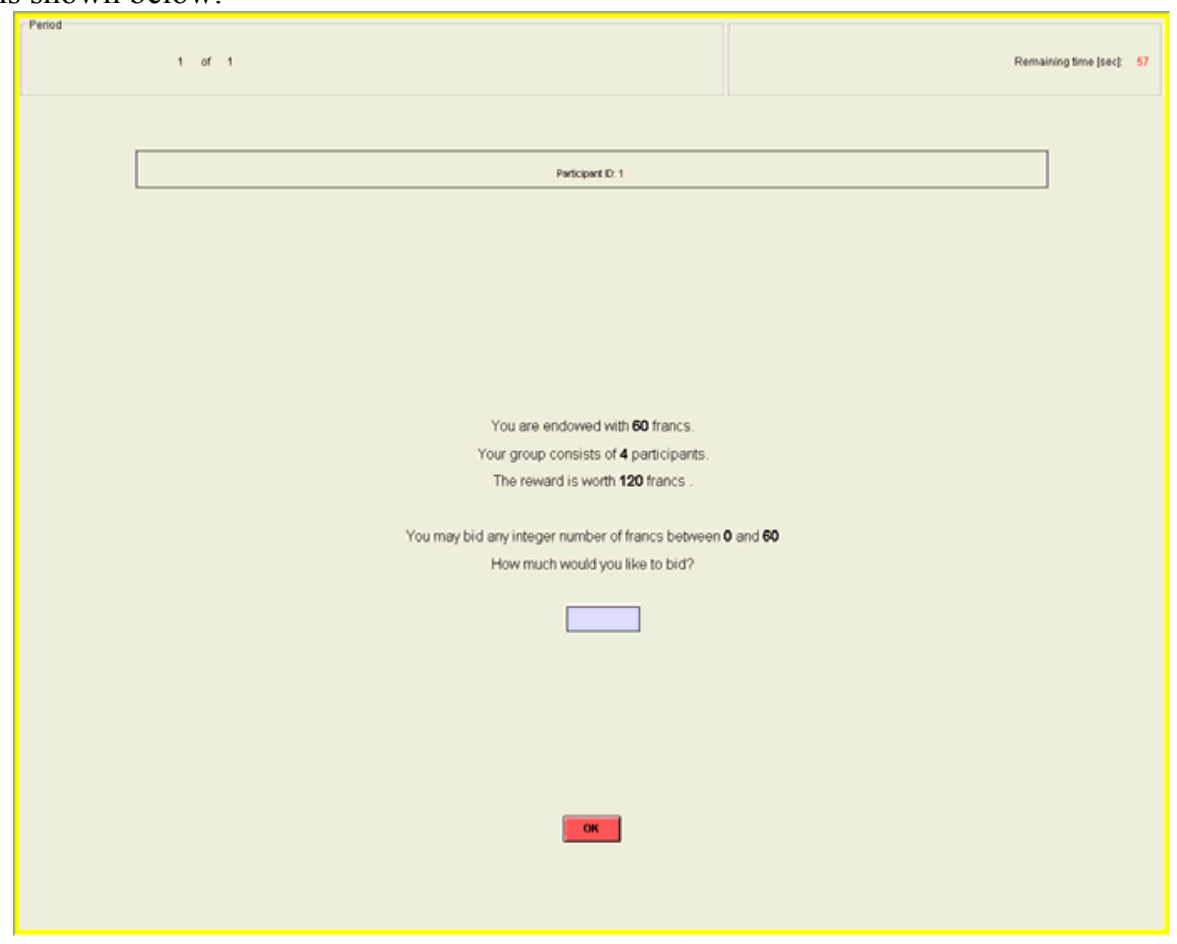

\section{YOUR EARNINGS}

\section{Decision Screen}

After all participants have made their decisions, your earnings for the period are calculated. These earnings will be converted to cash and paid at the end of the experiment if the current period is one of the five periods that is randomly chosen for payment. If you receive the reward your period earnings are equal to your endowment plus the reward minus your bid. If you do not receive the reward your period earnings are equal to your endowment minus your bid.

If you receive the reward: Earnings $=$ Endowment + Reward - Your Bid $=60+120-$ Your Bid

If you do not receive the reward: Earnings $=$ Endowment - Your Bid $=60-$ Your Bid

The more you bid, the more likely you are to receive the reward. The more the other participants in your group bid, the less likely you are to receive the reward. Specifically, for each franc you bid you will receive one lottery ticket. At the end of each period the computer draws randomly one ticket among all the tickets purchased by 4 participants in the group, including you. The owner of the drawn ticket receives the reward of 120 francs. Thus, your chance of receiving the reward is given by the number of francs you bid divided by the total number of francs all 4 participants in your group bid.

Chance of receiving $=\frac{\text { Your Bid }}{\text { the reward }}=\frac{\text { sum of all } 4 \text { Bids in your group }}{\text { sid }}$

In case all participants bid zero, the reward is randomly assigned to one of the four participants in the group.

\section{Example of the Random Draw}

This is a hypothetical example used to illustrate how the computer is making a random draw. Let's say participant 1 bids 10 francs, participant 2 bids 15 francs, participant 3 bids 0 francs, and participant 4 bids 40 francs. Therefore, the computer assigns 10 lottery tickets to participant 1,15 lottery tickets to participant 2, 0 lottery tickets to participant 3 , and 40 lottery tickets for participant 4 . Then the computer randomly draws one lottery ticket out of 
$\mathbf{6 5}(10+15+0+40)$. As you can see, participant 4 has the highest chance of receiving the reward: $\mathbf{0 . 6 2}=\mathbf{4 0 / 6 5}$. Participant 2 has $0.23=15 / 65$ chance, participant 1 has $\mathbf{0 . 1 5}=\mathbf{1 0} / \mathbf{6 5}$ chance, and participant 3 has $0=\mathbf{0} / \mathbf{6 5}$ chance of receiving the reward.

After all participants make their bids, the computer will make a random draw which will decide who receives the reward. Then the computer will calculate your period earnings based on your bid and whether you received the reward or not.

At the end of each period, your bid, the sum of all bids in your group, whether you received the reward or not, and the earnings for the period are reported on the outcome screen as shown below. Once the outcome screen is displayed you should record your results for the period on your Personal Record Sheet under the appropriate heading.

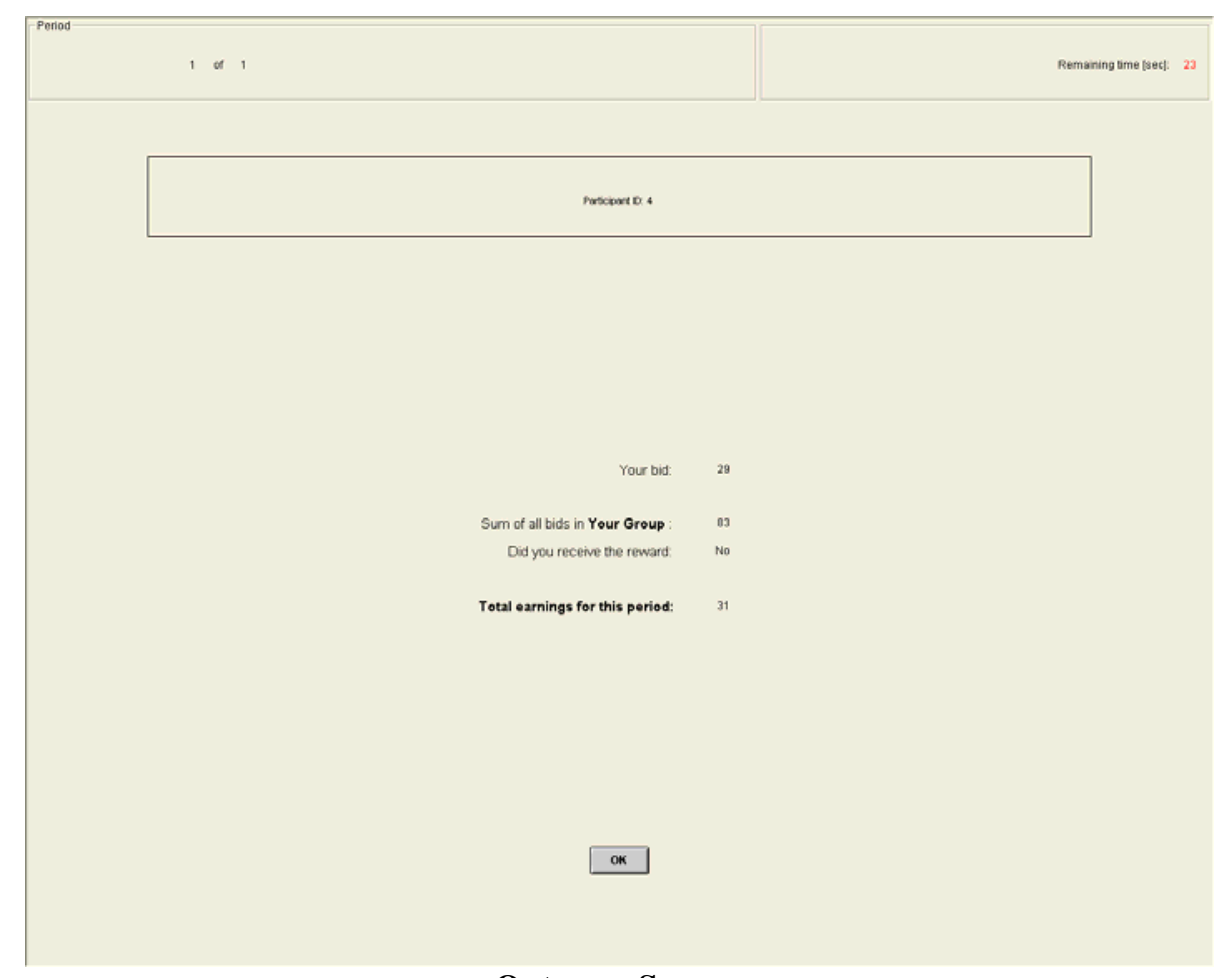

\section{Outcome Screen}

\section{IMPORTANT NOTES}

You will not be told which of the participants in this room are assigned to which group. At the beginning of each period you will be randomly re-grouped with three other participants to form a four person group. You can never guarantee yourself the reward. However, by increasing your contribution, you can increase your chance of receiving the reward. Regardless of who receives the reward, all participants will have to pay their bids.

At the end of the experiment we will randomly choose $\mathbf{5}$ of the $\mathbf{3 0}$ periods for actual payment in Part $\mathbf{2}$ using a bingo cage. You will sum the total earnings for these 5 periods and convert them to a U.S. dollar payment, as shown on the last page of your record sheet.

Are there any questions?

\section{INSTRUCTIONS FOR PART 3}

The third part of the experiment consists of $\mathbf{3 0}$ decision-making periods. The rules for part $\mathbf{3}$ are almost the same as the rules for part 2 . At the beginning of each period, you will be randomly and anonymously placed into a group of $\mathbf{4}$ participants. The composition of your group will be changed randomly every period. Each period you will be given an initial endowment of $\mathbf{6 0}$ francs. The only difference is that in part 3 , you will use this endowment to bid for two rewards (instead of one reward). The first reward is worth $\mathbf{9 0}$ francs and the second reward is worth $\mathbf{3 0}$ francs to you and the other three participants in your group. You may bid any integer number of francs between $\mathbf{0}$ and 60. After all participants have made their decisions, your earnings for the period are calculated in the similar way as in part 2.

If you receive the first reward: Earnings $=$ Endowment + First Reward - Your Bid $=60+90-$ Your Bid 
If you receive the second reward: Earnings $=$ Endowment + Second Reward - Your Bid $=60+30-$ Your Bid If you do not receive either reward: Earnings $=$ Endowment - Your Bid $=60-$ Your Bid

The more you bid, the more likely you are to receive either first or second reward. The more the other participants in your group bid, the less likely you are to receive any reward. Specifically, for each franc you bid you will receive one lottery ticket. At the end of each period the computer draws randomly one ticket among all the tickets purchased by $\mathbf{4}$ participants in the group, including you. The owner of the drawn ticket receives the first reward of 90 francs. Thus, your chance of receiving the first reward is given by the number of francs you bid divided by the total number of francs all 4 participants in your group bid.

Chance of receiving

the first reward

$$
=\frac{\text { Your Bid }}{\text { sum of all } 4 \text { Bids in your group }}
$$

In case you do not receive the first reward there is a second draw for the second reward. For the second draw computer draws randomly one ticket among all the tickets purchased by 3 participants in the group who did not receive the first reward (the participant who received the first reward is excluded from the second draw). The owner of the drawn ticket receives the second reward of 30 francs. Your chance of receiving the second reward is given by the number of francs you bid divided by sum of 3 bids made by the participants who did not receive the first reward.

Chance of receiving

the second reward Your Bid

Each participant can win at most one reward. In case all participants bid zero, the first and the second reward is randomly assigned to two of the four participants in the group.

\section{Example of the Random Draw}

This is a hypothetical example used to illustrate how the computer is making a random draw. Let's say participant 1 bids 10 francs, participant 2 bids 15 francs, participant 3 bids 0 francs, and participant 4 bids 40 francs. Therefore, the computer assigns 10 lottery tickets to participant 1,15 lottery tickets to participant 2, 0 lottery tickets to participant 3, and 40 lottery tickets for participant 4 . Then, for the first random draw, the computer randomly draws one lottery ticket out of $65(10+15+0+40)$. As you can see, participant 4 has the highest chance of receiving the first reward: $0.62=\mathbf{4 0 / 6 5}$. Participant 2 has $0.23=15 / 65$ chance, participant 1 has $0.15=10 / 65$ chance, and participant 3 has $\mathbf{0}=\mathbf{0} / \mathbf{6 5}$ chance of receiving the first reward.

After all participants make their bids, the computer makes a first random draw which decides who receives the first reward. Let's say that participant 4 has received the first reward. Then, for the second random draw, the computer randomly draws one lottery ticket out of $25(10+15+0)$. Since participant 4 has already received first reward he is excluded from the second draw. Now, as you can see, participant 2 has the highest chance of receiving the second reward: $0.6=\mathbf{1 5} / \mathbf{2 5}$. Participant 1 has $0.4=15 / 25$ chance and participant 3 has $0=0 / 25$ chance of receiving the second reward.

To summarize, all participants will make only one bid. After all participants have made their decisions, the computer will make two consecutive draws which will decide who receives the first and the second reward. Regardless of who receives the first and the second reward, all participants will have to pay their bids. Then the computer will calculate your period earnings based on your bid and whether you received either reward.

At the end of each period, your bid, the sum of all bids in your group, whether you received the first reward or not, whether you received the second reward or not, and the earnings for the period are reported on the outcome screen. Once the outcome screen is displayed you should record your results for the period on your Personal Record Sheet under the appropriate heading.

At the end of the experiment we will randomly choose 5 of the $\mathbf{3 0}$ periods for actual payment in Part $\mathbf{3}$ using a bingo cage. You will sum the total earnings for these 5 periods and convert them to a U.S. dollar payment, as shown on the last page of your record sheet.

Are there any questions? 


\section{Economic Science Institute Working Papers}

2009

09-04 Sheremeta, R. Experimental Comparison of Multi-Stage and One-Stage Contests.

09-03 Smith, A., Skarbek, D., and Wilson, B. Anarchy, Groups, and Conflict: An Experiment on the Emergence of Protective Associations.

09-02 Jaworski, T. and Wilson, B. Go West Young Man: Self-selection and Endogenous Property Rights.

09-01 Gjerstad, S. Housing Market Price Tier Movements in an Expansion and Collapse.

2008

08-10 Dickhaut, J., Houser, D., Aimone, J., Tila, D. and Johnson, C. High Stakes Behavior with Low Payoffs: Inducing Preferences with Holt-Laury Gambles.

08-09 Stecher, J., Shields, T. and Dickhaut, J. Generating Ambiguity in the Laboratory.

08-08 Stecher, J., Lunawat, R., Pronin, K. and Dickhaut, J. Decision Making and Trade without Probabilities.

08-07 Dickhaut, J., Lungu, O., Smith, V., Xin, B. and Rustichini, A. A Neuronal Mechanism of Choice.

08-06 Anctil, R., Dickhaut, J., Johnson, K., and Kanodia, C. Does Information Transparency Decrease Coordination Failure?

08-05 Tila, D. and Porter, D. Group Prediction in Information Markets With and Without Trading Information and Price Manipulation Incentives.

08-04 Caginalp, G., Hao, L., Porter, D. and Smith, V. Asset Market Reactions to News: An Experimental Study.

08-03 Thomas, C. and Wilson, B. Horizontal Product Differentiation in Auctions and Multilateral Negotiations.

08-02 Oprea, R., Wilson, B. and Zillante, A. War of Attrition: Evidence from a Laboratory Experiment on Market Exit.

08-01 Oprea, R., Porter, D., Hibbert, C., Hanson, R. and Tila, D. Can Manipulators Mislead Prediction Market Observers? 